\title{
Assess the impact of land use changes on erosion and sedimentation in Dak Uy reservoir
}

\author{
Le Thi Viet Hoa ${ }^{a}$, Pham Thi Huong Lan ${ }^{b}$, Le Minh Nguyet ${ }^{b}$ \\ ${ }^{a}$ Department of Water Resources Management - Ministry of Natural Resources and Environment: ltvhoa@ gmail.com/ \\ ltvhoa@monre.gov.vn \\ ${ }^{b}$ Thuyloi University (Water Resourses University), lanpth@wru.vn; nguyetlm410@wru.vn
}

Keywords: Land use; reservoir,

\section{Abstract:}

Vietnam has about 6648 irrigation reservoirs with a total capacity of about 60 billion cubic meters. Up until now, there are 1,129 reservoirs of all types in the Central Highlands, most of them are smaller than 1 million $\mathrm{m}^{3}$ (in particular, Kon Tum has 70 lakes and 99 lakes in Gia Lai). In recent years, due to vegetation cover changes, there are an increase in surface flow, surface erosion and sedimentation of reservoirs. Therefore, it is necessary to assess the impact of land use change on erosion and sedimentation in Dak Uy reservoir in the Sesan river basin.

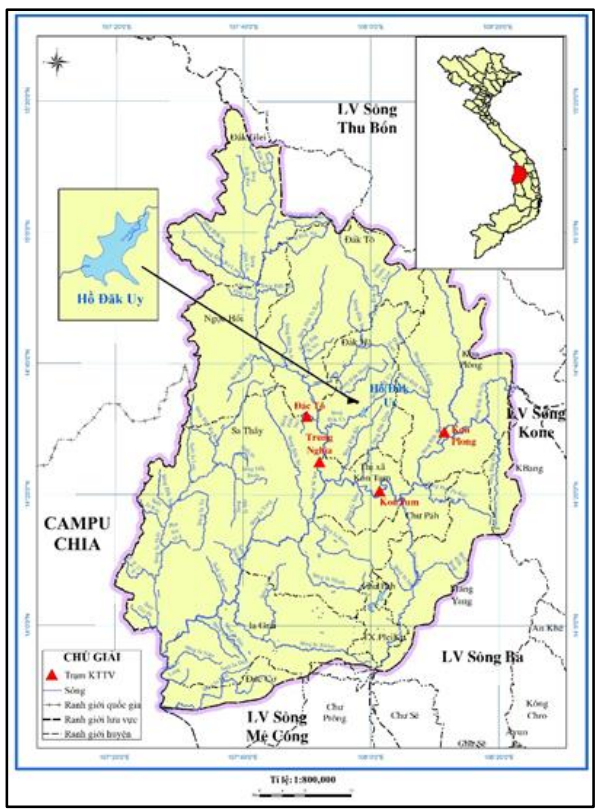

Figure 1. Location map of Sesan river basin and Dak Uy lake
The Sesan River flows through the Gia Lai and Kon Tum province in Vietnam before entering the Ratanakiri and Stung Treng province in Cambodia. The coordinates of the Sesan catchment area in Vietnam are $107^{0} 36^{\prime} 50^{\prime \prime}$ to $107^{0} 40^{\prime} 58^{\prime \prime}$ east longitude and $13^{\circ} 45^{\prime} 35^{\prime \prime}$ to $15^{\circ} 15^{\prime} 38^{\prime \prime}$ north latitude.

DakUy reservoir was built in geographical position $14^{0} 32^{\prime} 30$ north latitude and $107^{\circ} 58^{\prime} 10^{\prime \prime}$ east longitude in Dak Uy commune, Dak Ha district, Kon Tum province. Dak Uy reservoir is located on Dak Uy river which is the first level branch of Krong PoCo river in the Sesan river basin, in village 6, DakUy commune, Dak Ha district, Kon Tum province. Location of the construction is on the east of National Highway 14 and $20 \mathrm{~km}$ from Kon Tum town to the North. Located on the right of the DakUy branch is the DakProng stream, and it is also the second level branch of the Krong PoCo river. Located on DakProng stream is Dak Prong reservoir.

The temperature varies between $19.7^{\circ} \mathrm{C}$ and $24.2^{\circ} \mathrm{C}$. Rainfall begins in April with about $86 \mathrm{~mm}$. The highest precipitation, of $482.4 \mathrm{~mm}$, occurs in August. In December, rainfall declines sharply to about $1.5 \mathrm{~mm}$. Cultivation is done mainly in the wet season, which increases soil erosion and run-off. Slopes lose from 100 to 200 tons of soil/hectare/year. This translates to a nitrogen loss of between 150 kilograms and $200 \mathrm{~kg}$, a phosphate loss of between $30 \mathrm{~kg}$ to $60 \mathrm{~kg}$, and a potassium loss of between $130 \mathrm{~kg}$ and $200 \mathrm{~kg}$.

There are eight main soil groups on the Sesan catchment: The gley group (GI) covers 1,761 ha $(0.15$ percent of the area) in the northern districts except Dak Glei - The newly changed group (CM) covers 2,417 ha ( 0.21 percent) and is found in the Kon Tum, Dak Ha and Sa They districts - The gray group (X) covers 857,108 ha (73.76 percent) and is found throughout the region - The fluvial group (P) occupies 17,812 ha (1.53 percent) and is usually found in the downstream of rivers and in Dak To, Dak Glei districts and Kon Tum, Plei Ku cities • The alite group (A) covers 6,865 ha ( 0.59 percent) and is found in Dak Glei and Dak To • The yellow-red group (F) covers 227,159 ha (19.55 percent) and is found in Pleiku city, Kon Plong, Chu Pah, Dac Doa, Duc Co and Ia Grai districts - The slope group covers 11,312 ha $(0.97 \%)$ and is found in Pleiku, Kon Tum, Chu Pah, Dac Doa, and Ia Grai - The bare topsoil (E) covers 23,966 ha (2.06 percent) and is found in Kon Tum, Ia Grai, and Sa Thay districts.

The results of using SWAT model to assess the impact of the land use change on the flow and erosion of the Sesan river basin according to the vegetation status of 1983, 1993 and 2005 are illustrated accordingly belows:

Table 3.3: Calculated results according to SWAT model

\begin{tabular}{|c|c|c|c|c|c|}
\hline \multirow[b]{2}{*}{ Year } & \multirow[b]{2}{*}{ Average annual rainfall $(\mathrm{mm})$} & \multirow[b]{2}{*}{ Qmax (m3/s)/Peak time } & \multicolumn{2}{|c|}{ Total surface flow } & \multirow[b]{2}{*}{$\begin{array}{c}\text { Erosion } \\
\text { (t/ha) }\end{array}$} \\
\hline & & & $\begin{array}{l}\text { Flood season } \\
(\mathrm{mcm})\end{array}$ & $\begin{array}{c}\text { Dry season } \\
(\mathrm{mcm})\end{array}$ & \\
\hline 1983 & 1582.1 & $504.01 \mathrm{~m}^{3} / \mathrm{s}-7 / 9 / 1983$ & 3520.79 & 862.68 & 11.8 \\
\hline 1993 & 1528.8 & $432.6 \mathrm{~m}^{3} / \mathrm{s}-3 / 10 / 1993$ & 2123.86 & 636.46 & 11.44 \\
\hline
\end{tabular}




\begin{tabular}{|c|c|c|c|c|c|}
\hline \multirow[b]{2}{*}{ Year } & \multirow[b]{2}{*}{ Average annual rainfall $(\mathrm{mm})$} & \multirow[b]{2}{*}{ Qmax (m3/s)/Peak time } & \multicolumn{2}{|c|}{ Total surface flow } & \multirow[b]{2}{*}{$\begin{array}{c}\text { Erosion } \\
\text { (t/ha) }\end{array}$} \\
\hline & & & $\begin{array}{l}\text { Flood season } \\
(\mathrm{mcm})\end{array}$ & $\begin{array}{c}\text { Dry season } \\
(\mathrm{mcm})\end{array}$ & \\
\hline 2005 & 1798.2 & $553.82 \mathrm{~m}^{3} / \mathrm{s}-8 / 8 / 2005$ & 2767.28 & 676.3 & 15.03 \\
\hline
\end{tabular}

In the same basin, in 1983 and 1993, average annual rainfall across the basin was approximately equal (in 1993 the rainfall was greater than that in 1983 around $50 \mathrm{~mm}$ ), but different land cover conditions gave different flow results. In 1993, the area of forest increased dramatically compared to 1983, both in terms of quantity and quality of forest, the peak flood was reduced and the total flow in flood season dropped significantly, whereas in the dry season, the figure also fell which indicated that the effect of planting is clear. Rain intensity of 1993 is smaller than that of 1983, hence the erosion in 1993 is lower than that of 1983.

In 2005, due to heavy deforestation, the area of forest in the basin was reduced and the area of cultivating fields rises compared to 1993, the flow increased compared to that of 1993. However, the reason of increasing flow and erosion It also resulted from the increase in annual average rainfall compared to 1993. The above results indicate that afforestation in the basin has created a good vegetation cover to reduce the possibility of washing away the nutrition of soil. Thus, the rain factor also plays an important role in forming the flow and causing erosion of the basin.

The factor of vegetation cover has a great impact on the ability to form runoff and erosion in the basin. The impact of forests on flows and sediments depends on the proportion of forest area in the basin and forest distribution in that area. According to the above results, the forest status in 2005 has better regulating effect if the forest coverage reaches about $60-65 \%$. Thus, if the forest coverage is increased to about $60-80 \%$ for the whole region, it will increase the flow regulation ability, limit as much as possible erosion and soil washing away, protect soil, preserve water regulation ability, making rivers and streams have stable flow all year round, and creating many products from land and forests.

When changing the area used in the basin as above, there was a change in flood peak, the total flood in the dry season and flood season, plus erosion and nutrition. When changing the area of rich forest to non-forest, shrub or cultivation area, changes in flood peak as well as in flow volume was clear. Rich forests in the basin were mainly protection forests with a coverage of $60 \%$. When converted to non-forest or shrub, the flow volume in the flood season increased 219.78 mcm (approximately 9.38\%) while the flow volume in the dry season fell by $32.33 \mathrm{mcm}$ (around 5.35\%). The total erosion in the basin surface also rise 1.45 ton/ha (about 11.25\%). This result prove that forest play integral parts in flood regulation and erosion reduction in the basin.

Calculated results from the model show that the level of erosion in the area corresponding to the forest status in 2005 compared to the figures of 1983 and 1993 is larger due to the change of the land cover in the basin, the area of nonforest area of 2005 decreased significantly compared to 1983 and 1993 (the figure for 1983, 1993 and 2005 was $53.68 \mathrm{~km}^{2}$ (around $64.68 \%$ ), $34.67 \mathrm{~km}^{2}$ (equivalent to $41.78 \%$ ), $28.64 \mathrm{~km}^{2}$ (about $34.51 \%$ ) respectively. According to the forest status statistics in 2005 compared to the forest status in 1983 and 1993, although there was an increase in forest type, the area was still small, area of non-forest or shrub remained large. Calculation results indicate that corresponding to 2005 forest status, the amount of suspended sediment to the lake is: Go $=2340$ (ton/year), while with the 1983 forest status, the amount of suspended sediment to the reservoir is 2129 (ton/year) and the figure for 1993 is $\mathrm{G}=1828$ (ton/ year), so when the forest area in the basin is reduced, the amount of sediment in the reservoir will increase, especially during the flood season. In the dry season, in general, when the forest area decreases, the flow tends to increase, the level of surface erosion also increases and this increase is significant in the flood season, while in other seasons, there is a tendency of more clearly reduction.

Altering the land use scenario in accordance with the current vegetation cover status or changing land use structure to assess the impact of land use changes and soil structure on the flow and erosion in the Sesan river basin. When changing the area of rich forest to non-forest, shrub or cultivation area, changes in flood peak as well as in flow volume was clear. When changing the area of each forest types into the cultivation land, which means changing from tree species with high water holding capacity to low water holding capacity, it increased flow during flood season and reduced flow in the dry season. Corresponding to the increase and decrease of flood in the flood season and dry season, the volume of erosion in the basin also changes as we change the forest area in the basin to different types of forests. When the forest has a large coverage, it will reduce rain intensity which causes erosion in the basin. It is clear that erosion increases when the level of human intervention is increased through land use processes in the basin. 